\title{
"Guidelines" for sustainable rehabilitation of the rural architecture
}

\author{
S.F. Musso \& G. Franco \\ Department of Sciences for Architecture, Polytechnic School, University of Genoa, Genoa, Italy
}

\begin{abstract}
For a long time, scholarly attention has been devoted to few "exemplary buildings" rich in history and of aesthetic values, whereas it was almost ignored the vast heritage of rural buildings and constructions. Retaining walls, paths or ovens, rich lowland farms or poor buildings scattered among the mountains, have often been regarded as simple objects of which it was necessary to decide the fate, in ways more or less distracted and under various demands. It was thus often missed the recognition of the full dignity of many cultural buildings belonging to the so-called "peasant or rural world". Several new challenges regard now the conservation, the sustainable re-use and the compatible rehabilitation of this heritage, respectful of its features, of its layered consistency and of its values, aiming at enhancing its livability and improving its energetic behavior. The paper deals with these topics and offers an overview of the researches carried out by the authors in this field.
\end{abstract}

\section{STUDIES AND RESEARCHES ON RURAL ARCHITECTURE IN NORTHERN ITALY}

In the last years the authors developed and coordinated several studies on the topic that have been presented through the publication of specific "Guides for conservation, maintenance and rehabilitation of Rural Architecture" in different protected areas, mainly in Northern Italy.

Among them are: the Regional Parks of Aveto and Beigua, beyond the National Park of the "Cinque Terre" in Liguria Region; the GAL (Groups of Local Actions) of "Langhe Roero" and of "Mongioie", in Piedmont (in collaboration with the Polytechnic of Turin); the Park of "Val d'Intelvi", in Lombardy (in collaboration with the Polytechnic of Milan) and the Sardinia Region (in collaboration with the University of Cagliari).

All the "Guidelines" address the vast and complex theme of rural architecture in which many studies have been devoted, at least for a century or so, with the help of many disciplines. In recent years, however, there has been a renewed and growing interest in the artifacts associated with the use of agriculture, forestry or pastoral care of our territories and to their fate. To it, however, is not yet a real awareness of the many aspects of the problem, even for the lack of new contributions after the great systematic researches of the thirties and the fifties of the last century, at least in Italy.

Many studies, however, are rarely departed from an explicit definition of their scientific object, the "rural or vernacular", in fact, because of the extreme difficulty to proceed with its clear delimitation. It is often derived from a simplistic attitude that looked only to superficial aspects of those buildings, isolating them from the wider horizon of historical, social, economic and environmental nature of which they always are a fundamental expression.

For a long time, rural architecture has thus been confined to the domain of "spontaneity" or "natural" (not to say, of the "irrationality"), ignoring the fact that it is not the product of a disordered and random human activity, with no rules, patterns, strong links with history, the environment and its resources, the expression of a state of equilibrium now almost entirely forgotten, and sometimes irreparably destroyed. In contrast, the traditional rural architecture is the result, never fully inclusive of profound influences exercised at all times and places, from economic, social, technical, scientific and cultural communities who created, lived in and used every specific flap of the territory.

Above all, geographers, who almost alone initially studied this vast and widespread built heritage, considered the slow process of transformation of rural architecture through the ages as the result of a continuous and mechanical adaptation to external conditions, the production needs and housing, forgetting that, in any case, these processes are of deep cultural nature.

Then, there is always a strong tendency to identify rural architecture with the generic concept of "folk architecture" or "minor architecture", highlighting 
the lack of "courtly or monumental" characters in those buildings. We forget, in this way, that this heritage has extraordinary cultural values and formal, making it a valuable "historical document", as well as a useful (but fragile and irreplaceable) material resource. The rural architecture, in fact, although it is not the result of "intentional design of an architect," is always the product of complex intentions and of rich interactions between several subjects and different needs

Taking into account these premises, the studies presented here bring a contribution to the discussion on the topic, by considering the rural architecture as a "system of systems" and not as the "simple sum" of systems, or of sub-systems, physically and logically separated from each other. A rural building, like any other pre-industrial architecture, it is thus regarded as a "unit", that is an "irreducible synthesis" of various constituent elements, surpassing the paradigms of the modern "prescriptive technology."

That building, in fact, is the product of an ancient "conventional technology", now almost completely forgotten and that we need to re-take possession of, as it may still be useful to the active protection of the built heritage and the rural landscape. A building, on the other hand, can be always studied by adopting different ways of reading it that correspond to the many problems that the act of building faces.

Nevertheless, it remains always the same building, or a manufactured unit, even if sometimes it appears a wealth of different constructive result of the historical events that have marked its existence (uses, abandonment, reconstructions, reuse, adaptations, extensions ...). That building represents, in a sense, the synthesis of all the aspects that our investigations, in an attempt to achieve more in depth knowledge, tend to separate and select as if they were completely independent. The requirements of the use, translated into the succession of spaces, in their conformation and organization, in plan and elevation, the requirements of security and stability, absolved from all its resistant structures, major and minor, shaped according to a specific structural design (conception) and, finally, the properly compositional intentions, translated into the apparent forms of the building, in fact, are all present together in it and are all essential for its existence.

These are the synthetic scientific and cultural premises from which our studies, surveys and elaborations started and that have been afterwards developed in the various "Guidelines..." in question.

\section{KEY ASPECTS OF SUSTAINABILITY IN RURAL ARCHITECTURES}

The paper thus intends to highlight the following main key issues that are related to the general theme of the sustainability of the future recovery of this specific heritage according to the quoted studies and in relation with the constructive features of the traditional buildings (in their relationships with the landscape) and with regard to the challenges of their safeguard, conservation and rehabilitation.

The availability of natural materials and their traditional uses, first of all, is at the basis of the best possible traditional constructive solutions adopted for saving the different sources of energy that were needed to heat them. This circumstance allowed "sustainable" conditions for living in their interiors, within the climatic conditions of the examined territories and in the given conditions of the ages they were built (or transformed).

Moreover, the traditional settlement and "modelling" of the territory have been for centuries signed by the use of the products of some "closed" cycles, such as the forest and the agricultural economy, that inevitably gave life to a sustainable land use.

The traditional constructive techniques that characterize the rural buildings are thus the result of the capability of their inhabitants and builders to leave in the various climatic zones using (but never wasting) their finite resources and which can be still adopted (necessarily reinterpreted) for the maintenance, repair and structural strengthening of the traditional rural heritage.

In each specific climatic zone, the employed materials, with some interesting constructive details, must be therefore considered as a way to diminish the loss of heat from the interior towards the outdoor (or to maintain it "inside"), or to prevent the penetration of the cold inside the building from outside. They are, at the end, more than simple "formal" features and for this reason they should be carefully conserved or even re-proposed within the future reparation and upgrading interventions.

Some innovative solutions, in terms of new materials, or of innovative constructive techniques, can (or must) of course be adopted for the same purposes and to realize new interventions, always dialoguing with the existing parts but only if they are really compatible with them (mechanically, physically, energetically...) and if they respect their fundamental features, their historically "layered substance" and the landscape they are inserted in.

The traditional morphologies of the rural buildings (dimensions, relationships with the ground, disposition, shapes and dimensions of the openings, thickness of the walls etc.) must be then considered as the "smart" final products (or result) of an ancient "material culture". Its sustainability, on the other hand, has been already assessed by the passing of the centuries, also for what regards their behaviour in relation with the climate, the environmental influences and the different solicitations and risks they are exposed to (temperature fluctuations, rain and snow precipitations, flood, soil erosions and movements, seismic solicitations...). 
For all these reasons, there is also a fundamental need for continuous and programmed maintenance and care of the most fragile constructive elements and materials, always choosing low-impact intervention techniques that can be compatible with the features of the existing buildings.

\section{MAIN GOALS OF THE "GUIDELINES”}

There are, of course, some differences between the different studies initially quoted, because of the characters (physical, geographic, climatic...cultural), of the involved areas and of their built rural heritage. Nevertheless, they all share some common and basic elements that reflect the cultural and technical setting of the research team. For this reason, the paper deals with the characteristics and the common problems and applications to the various quoted experiences, rather than with their differences

All the different "Guidelines..", in strict relationship with their territory, aim in fact at:

-providing rigorous elements of knowledge of the architectural and constructive features of the rural artefacts of the involved areas;

-giving concrete advice for maintenance, conservation and rehabilitation interventions of the existing rural buildings spread in the landscape and outside its historic villages, in order to preserve their complex features and values, enhancing their liveability and their sustainable re-use, beyond their energetic behaviour, without wasting their already experimented qualities under this point of view;

-offering a wide overview on the available traditional, or even innovative, technical solutions to solve the surveyed problems of these buildings, selecting those which can be applied respecting their material features and immaterial and the landscape they are part of;

-suggesting an adequate methodological approach to achieve effective outcomes through the recovery/rehabilitation interventions, based on the preliminary knowledge of the building features, of their material decay or stability problems, but also of the possible threats and of the needs for their adaptation to the contemporary standards only if (and within the limits in which) they are compatible with the safeguard of their features;

-offering these "eligible solutions" as a simple tool that can support the technical standard of more general planning instruments, and that should not be intended as a legal and imperative or compulsory regulation, in general terms;

-allowing and requiring the continuous implementation of these potential solutions, by the part of the local administrators and of the professionals active on the field that, while working on real cases, may transform the various "Guidelines.." in 'living' instruments which may even be modified on the base of their application and of the new acquired knowledge deriving from an open process of self-learning and self-enhancement.

\section{PRELIMINARY FIELD STUDIES}

Wide and deep surveys have been carried out, in each examined territory, to identify the main constructive and architectural features of the traditional buildings spread in the countryside and the most recurrent problems of material decay and of structural defects or risks that affect them.

The traditional rural buildings of each area have been thus recorded using first of all a "synthetic" data sheet and some of them (selected on the basis of this first phase, because really representative of the whole examined universe, under many points of view) have been analyzed in a more detailed way. Each selected building has been further on described together with the uses and the features of its surrounding open spaces.

Starting from the data collected during the survey and duly organized in an open and implementable data-base, the following main objectives of the "Guidelines.." have been clearly outlined:

-improving the quality of the maintenance processes and of the interventions for their reparation / rehabilitation, promoting a more effective safeguard of the ancient rural buildings;

-raising the awareness among the local communities towards the complex values of their traditional built heritage and of the cultural landscapes in which they are living only as provisional heirs;

-providing adequate technical solutions for the conservation and for the rehabilitation interventions of the old rural buildings and for their compatible and affordable (sustainable) adaptation to the modern uses, without destroying their identity nor losing their values;

\section{GENERAL CRITERIA FOR INTERVENTION}

At the building scale, the proposed general criteria for interventions mainly refer to the principle of the so named "minimum intervention" and require the fundamental respect of the material consistency and of the formal characters of the existing buildings that imply, among the others, the acceptance of the following fundamental requirements:

-respecting the building structural and morphological conception and acquired behaviour, layout and components, together with their existing material 
substance, through the privileged utilization of the traditionally used building materials;

-using traditional but also modern constructive and intervention techniques and materials which must be, in any case, compatible with the existing ones;

-adding new parts (only if strictly necessary for the conservation of the existing parts), rather than modifying the existing ones, always respecting the architectural identity of each building in its relationship with the surrounding environment and landscape.

\section{TECHNICAL INSTRUCTIONS FOR INTERVENTIONS}

The guidelines are organised in technical sheets, grouped into sections, according to the technological and constructive components of the buildings: (such as: general structure, masonry boxes types, walls, kind of masonries, roofs, floors, plasters and external surfaces, doors and windows, balconies, stairs, water plants, electrical services, etc).

Each section of the "Guidelines..." comprehends:

-the description of the examined constructive and technological features of the building, based on the data collected during the field survey that have provided the necessary information about recurrent morphologies, constructive techniques, materials and the dimensional data of the specific element;

-the description of the most frequent material degradation and stability problems and of the current technical requirements;

-some specific "guiding principles" useful to realize the possible interventions on the components of the existing building, based on the general criteria described above, and respectful of its material and architectural features;

-some images and analytical texts that can help the description of the interventions (in its realization phases) that have been considered not compatible with the above mentioned guiding principles, accompanied by short comments explaining the reasons for the negative judgement;

-two different levels of compatibility, with their specific guiding principles and their identified values, that are so defined: 1) compatible, that is "possible only under specific controlled conditions"; 2) clearly not compatible. Each of these two levels is linked to a specific list of related interventions and techniques duly supported by demonstrative drawings, pictures and descriptions;

-the description of the preliminary investigations (non-destructive) that are necessary to clearly identify the main (or the most common) causes of dete- rioration, decay or of structural instability of the different categories of buildings and components;

-this description is completed by some general advices for the elimination or for the adoption of contrasting actions against those causes and that should be carried out before any direct intervention upon the "physical bodies" of the buildings;

-an inventory of the various and "possible technical solutions", starting from the less invasive ones to the most impacting ones, in terms of transformative effects (considering: cleaning, disinfesting, dehumidification, maintenance, repair, replacement, insertion of new elements, etc.).

-for each intervention, the "Guidelines..." offer to the user: a clear declaration of its main goals, the detailed description of the phases necessary for its implementation, the materials that can be used, some warnings on safety matters and environmental compatibility, some general advices regarding the best way to realize the intervention on the construction site.

\section{CONCLUSIONS}

The various "Guides..." the paper deals with have been published and distributed at local level especially among inhabitants, civil servants, technicians, professionals and administrators involved in the rehabilitation processes of their rural heritage. Further, all the "Guidelines..." have been diffused among a wider national public conquering a widespread interest on a more general cultural level.

In the first case, the "Guides..." have been intended to provide a support to the protagonists of the rehabilitation processes of the analyzed heritage. Within this perspective, they have also been the main topic of some "training" courses organized by the responsible bodies that committed their preparation and managed by their authors, in order to positively influence the involved subjects, in different phases and with various responsibilities and aims, in the recovery of the rural heritage within the examined areas (Regional or National, Parks, GAL consortia of Municipalities, Regions etc.).

Moreover, in some cases, the "Guidelines..." have been officially inserted by the responsible Administrations within their planning and regulatory instruments, for the management of their territories. In these cases, the "Guidelines..." do not have a compulsory or imperative nature but can be used as a tool to examine and approve the interventions proposed by the private or public owners of the existing buildings to be recovered and restored. Moreover, they can be assumed as the basis to assign to the owners the available grants, in order to support their intervention if it they are designed and executed re- 
specting their suggestions. More than imperative rules, they must thus be intended and used as "suggestions" and "supporting" tools aimed at improving the quality of the rehabilitation process of the existing rural buildings. In this perspective they aim to express, first of all, a pedagogical and educative role, even before a simple technical one and the results till now acquired seem to be encouraging in this perspective.

The "Guida..." for the "Cinque Terre" National Park is the result of a research programme committed to the Department DSA of Sciences for Architecture of the University of Genoa, financed by the Regional Directorate for Cultural Heritage and Landscape of Liguria with the participation of the local Superintendence for Architectural Heritage and Landscape and the Regione Liguria.

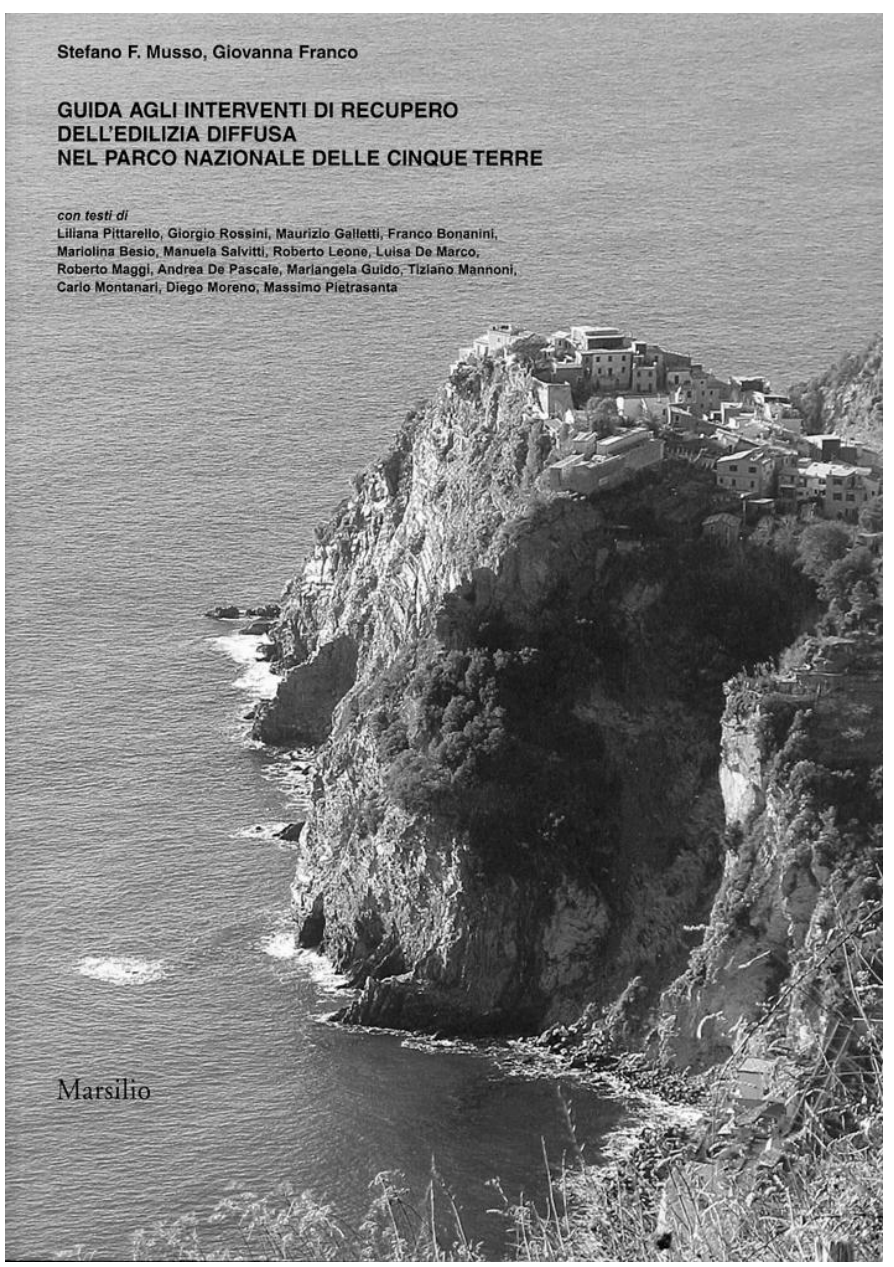

Figure 1. The image above represents the cover of the book published by the authors in 2006: "Guida agli interventi di recupero dell'edilizia diffusa nel Parco Nazionale delle Cinque Terre" (Venezia, Marsilio Editori).

\section{NOTE}

The research activities presented in the paper have been developed by an interdisciplinary group constituted by the department DSA of the University of Genoa, with the scientific responsibility of prof Giovanna Franco and prof. Stefano F. Musso. The researches have been committed and partly financially supported by several Institutions among which are: MiBACT-Ministry of Cultural Goods and Activities and Turism, its Regional Directorate for Cultural Heritage and Landscape (arch. Liliana Pittarello, arch. Maurizio Galletti, Directors, arch. Manuela Salvitti, arch. Luisa De Marco) and the Superintendence for Architectural Heritage and Landscape of Liguria, Regione Liguria, Ente Parco Nazionale delle Cinque Terre; Ente Parco Regionale dell'Aveto; Ente Parco Regionale del Monte Beigua; GAL Moongioie e GAL Langhe-Roero, Regione Piemonte (prof. Daniela Bosia); European Commission - Culture 2000 and INTERREG IIIA e IIIB programmes; Comunità Montana Val d'Intelvi, Regione Lombardia (prof. Stefano Della Torre), Regione Sardegna (prof. Antonello Sanna)

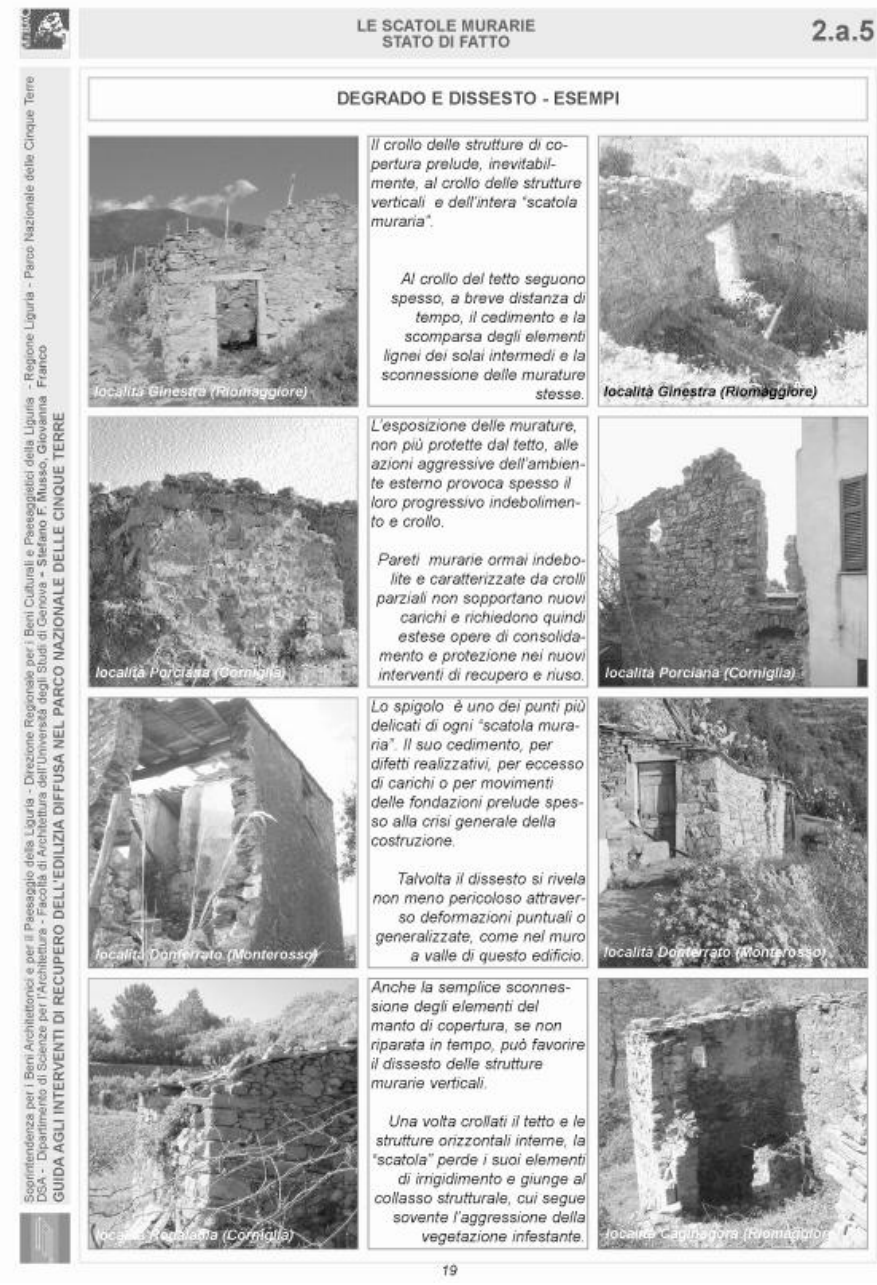

Figure 2. A inner page of the "Guida..." for the "Cinque Terre" National Park showing and explaining the recurrent problems of material decay and of structural instability that affect the traditional "masonry boxes" of the rural buildings of the Park. 


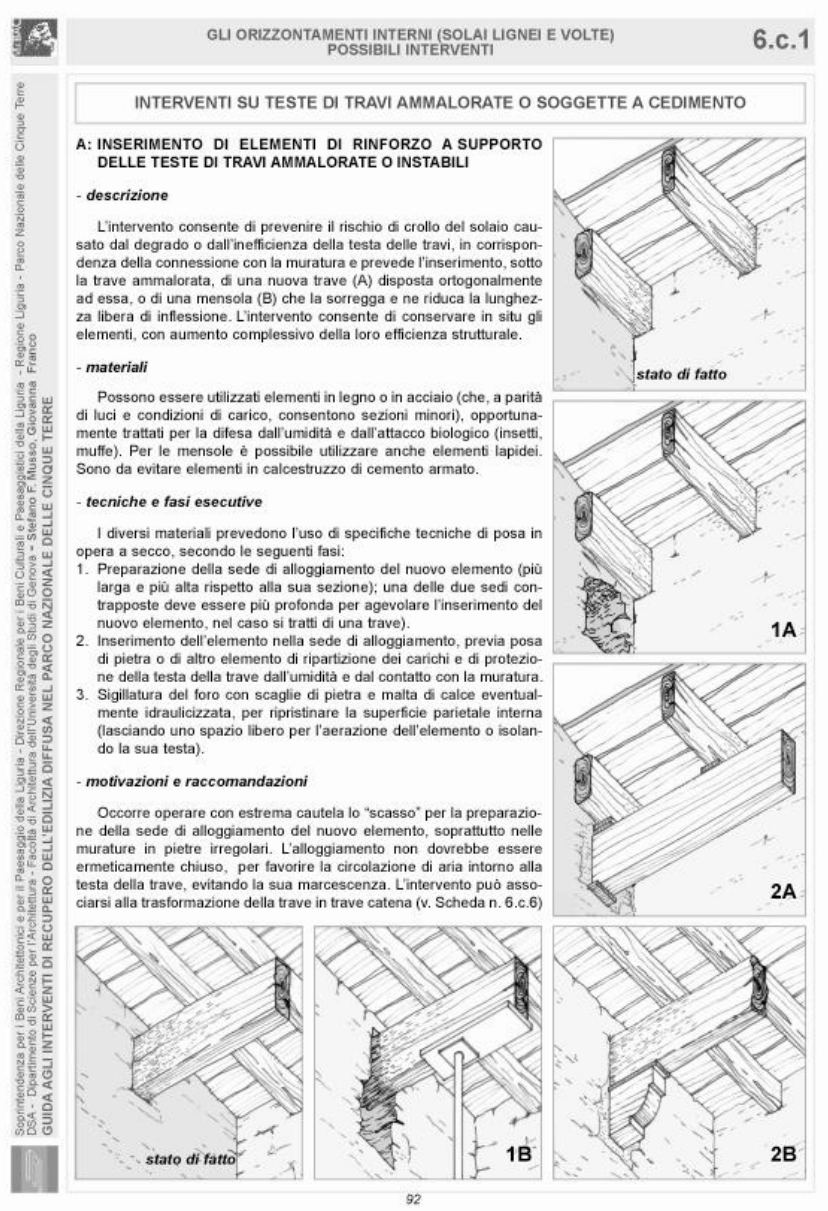

Figure 3. This inner page of the "Guida..." for the "Cinque Terre" National Park shows a possible intervention to recover a damaged timber ceiling, realized by inserting new elements supporting the fragile or ruined existing beams.

\section{REFERENCES}

Awtuch A., Baranowski A., Bobbio R. A et al., 2005. Rural architecture in Europe between tradition and innovation. Researches, ideas, actions, Alinea, Firenze

Aa.Vv., Guida alla manutenzione e al recupero dell'architettura rurale intelvese, 2013, Regione Lombardia, Comunità Montana Lario-Intelvese, provincia di Como, A.G. Bellavite srl, Missaglia (Lc) $\left(1^{\circ}\right.$ ed. Como 2006)

Bosia D., Franco G., Marchiano R., Musso S.F., 2004. Guida al recupero degli elementi caratterizzanti l'architettura del territorio del G.A.L. Mongioie, TipoArte, Bologna
De Marco, L., Franco, G. \& Magrini, A., 2013. Guidelines for eco-efficiency in the UNESCO site of Cinque Terre: an example of best practice. In, Boriani, M. (Ed.), Built Heritage 2013, Monitoring Conservation and Management, Milan: Centro per la Conservazione e Valorizzazione dei Beni Culturali.

De Marco L., Salvitti M., 2003. The guide for the rehabilitation of rural buildings in the National Park of "Cinque Terre”, an instrument for the management of the transformations of the built environment within a cultural landscape, in Atti $7^{\circ}$ Colloquio internazionale della Organizzazione delle Città Patrimonio Mondiale, "Keeping Heritage alive", Rodi, 23-26 Settembre (CD Rom)

Franco, G., 2013. Innovazione e sostenibilità in un paesaggio culturale, in: "Technè" 5, 129-134.

Franco, G., 2012. Sustainability and Heritage: a challenge for contemporary culture. In Crisan, R., Kealy, L., Musso, S. F. \& Franco. G. (Eds), Conservation/Regeneration: The Modernist Neighbourhood, Leuven: EAAE Transactions on Architectural Education (58).

Franco, G. \& Magrini, A., 2013. Eco-efficienza del patrimonio storico in un paesaggio culturale, in Lucchi, E. \& Pracchi, V. (Eds.), Efficienza energetica e patrimonio costruito. La sfida del miglioramento energetico nell'edilizia storica: 231-247. Milano: Maggioli editore.

Franco G., Musso S. F., 2011. Guidelines for Conservation and Maintenance of Rural Architecture in Protected Areas, in: Second International Conference on Conservation of Architecture, Urban Areas\& LAndscapes (Heritage 2. Amman, 13-15 March 2011, p. 179-194, AMMAN:CSAAR press.

Franco G., Musso S. F., 2003. Una Guida Per Il Recupero Nel Parco Delle Cinque Terre. In: Aa. Vv.. Soluzioni ecocompatibili nella configurazione del paesaggio rurale. vol. 1, p. 323-332,Liguori, Napoli

Musso, S.F., Franco, G. \& Gnone, M., 2008. Architettura rurale nel Parco del Beigua. Guida alla manutenzione e al recupero. Venezia: Marsilio Editori.

Musso, S.F. \& Franco, G., 2006. Guida agli interventi di recupero dell'edilizia diffusa nel Parco Nazionale delle Cinque Terre. Venezia: Marsilio Editori.

Musso S.F., 2005. Rural architecture in Europe: studies, concepts and management tools., in A. Awtuck, A. Baranowskj, R.A. Bobbio, A. Bohm, D. Bosia, D. Bouillon, L. De Marco, G. Franco, S. Hirshi, B. Lipinska, G, Moretti, S. F. Musso, K, Szareiko. Rural architecture in Europe between tradition and innovation. Researches, ideas, actions, Alinea, Firenze

Musso S.F., G. Franco, 2001. Il destino dell'architettura rurale, in "Recuperare l'edilizia", vol. 23, p. 66-78

Musso, S.F. \& Franco, G., 2000. Guida alla manutenzione e al recupero dell'edilizia e dei manufatti rurali. Venezia, Marsilio Editori

Musso S. F., De Marco L.,2008. La gestión de la transformación de un paisaje aterrazado. Rehabilitación del parque nacional "Cinque Terre", Liguria (Italia), in: Casanovas $\mathrm{X}$. (ed.). Experiencias de rehabilitación mediterráneas. vol. 1, p. 67-74, Barcelona, RehabiMed 